\title{
Grindability Studies of Mineral Materials of Different Morphology
}

\author{
Veerendra Singh* \\ R\&D, Tata Steel Limited, India \\ *Corresponding author: Veerendra Singh, R\&D, Tata Steel Limited, Jamshedpur, India
}

Submission: 侮 October 03, 2018; Published: 眥 November 26, 2018

\begin{abstract}
These studies have been carried out to compare the grinding characteristics of different morphological mineral matters. Coal, dolomite, manganese and iron ores samples were ground using a ball mill in different grinding conditions (dry and wet) and at different critical speed $\left(\mathrm{R}_{45 \%}, \mathrm{R}_{70 \%}\right.$ and $\left.\mathrm{R}_{90 \%}\right)$ during wet grinding. Results are compared considering the relative impact on particle size and shape. Materials were ground in a lab scale ball mill for 2 hours with steel balls and size analysis of products were carried out using different size sieves $(1,0.5,0.25,0.15,0.106$ and $0.053 \mathrm{~mm})$. Microscopic studies were carried out to know the effect of different grinding conditions on particle properties. Light, fine grain and soft dolomite shows only $8 \%$ reduction in $\mathrm{D}_{80}$ whereas heavy, friable and hard manganese ore shows a $29 \%$ reduction in $\mathrm{D}_{80}$ for similar dry and wet grinding conditions. It was found that light materials are less sensitive towards mill speed (R) during wet grinding. Energy calculations indicated that wet grinding is less efficient for low density and soft materials than high density and hard materials. The relative increase in the fineness $\left(\mathrm{D}_{80}\right)$ for coal, dolomite, manganese ores and iron ores were $8.9,6.5,25$, and $15.8 \%$, respectively for wet and dry grinding. Variation in D/L indicates that abrasion is a prominent phenomenon in dry grinding and chipping is more prominent in wet grinding especially for material with bedded structures.
\end{abstract}

Keywords: Grinding; Minerals matters; Morphology; Shape; Size reduction

\section{Introduction}

Comminution is a popular process in mineral, cement, pharmaceutical, refractory, fertilizer and chemical industries. Varieties of materials are ground using conventional grinding methods but the impact of material properties on the grindability of these materials using the conventional machines is not yet fully explored. In mineral processing operations, size reduction causes significant energy consumption and impact subsequent processes, such as floatation, pelletization, etc. Various studies have been reported in the literature which revealed the dependence of grindability on material properties. Rumpf [1] proposed a detailed analysis of physical aspects of comminution for the better understanding of breakage characteristics of mineral matters [1]. Peukert [2] proposed measurable material properties describing the comminution performance of different materials. Strength and hardness are the key elements which dictate the breakage characteristics of materials during milling. Other materials properties, such as structure, density, porosity, and hydrophobicity, etc. also impacts material flow, particle flotability and shock wave propagation also play a significant role during grinding. It is reported in the literature that fracture propagation is significantly impacted by material density $[3,4]$. Some of the inherent material properties impact particle dispersion, flowability and mixing during grinding [5-9]. Brown \& Reddish [10] found that fracture toughness and density of rocks both depend on anisotropy and cleavage dominance which cause a linear relationship between these two parameters. Alber \& Brardt [11] reported that porosity, grain size, and grain-contact length also impact the fracture propagation. Shatter effect during impact fragmentation depends on the shock wave velocity in the material and at interfaces [12]. Yekeler \& Ozkan [13] studied the effect of wettability on grinding characteristics of calcite and found that relatively more hydrophobic surfaces are broken faster for the largest sizes. Liu et al. [14] studied the effect of effect of wet versus dry grinding on the rejection of pyrite and non-pyritic minerals from Pittsburgh No.8 Coal by flotation. Ozkan et al. [15] studied the kinetics of wet versus dry grinding of lignite by a porcelain mill and found that wet milling is more efficient to produce finer products. Kotake et al. [16] studied the effect of dry and wet grinding conditions on fineness and shape of particle size distribution of the product in a ball mill and found that effect of variation in ball size responds differently for dry and wet methods. He et al. [17] reported the effect of slurry rheology on the wet ultra-fine grinding of a limestone powder and revealed its effect on grinding energy. This study is carried out to understand variation in grinding characteristics of materials of different morphology during dry and wet grinding. It can be helpful to understand the applicability of effect of grinding in the emerging fields of scientific research, such as high-pressure roll grinding, grinding for nanoparticle generation, techno-chemical activation, polymorphism, etc. 


\section{Experimental Studies}

Coal, dolomite, manganese and iron ore samples were selected for experimental studies because these are the important raw materials for many industries such as steel, power, cement, etc. Material characterization, density measurement, screening, grinding and microscopic studies have been carried out using representative samples of mineral matters $[18,19]$.

\section{Materials}

Coal: High ash coal sample from Damodar Valley Coalfields in India has been collected for studies. These are brittle and high ash coal samples with finely associated carbonaceous material and inorganic minerals. Coal has bedded structure with $1.5 \mathrm{~g} / \mathrm{cc}$ density and Mohs hardness 2 . Coal samples were ground $<1 \mathrm{~mm}$ size for grinding studies. Figure 1 shows the soft and bedded structure of coal particles.

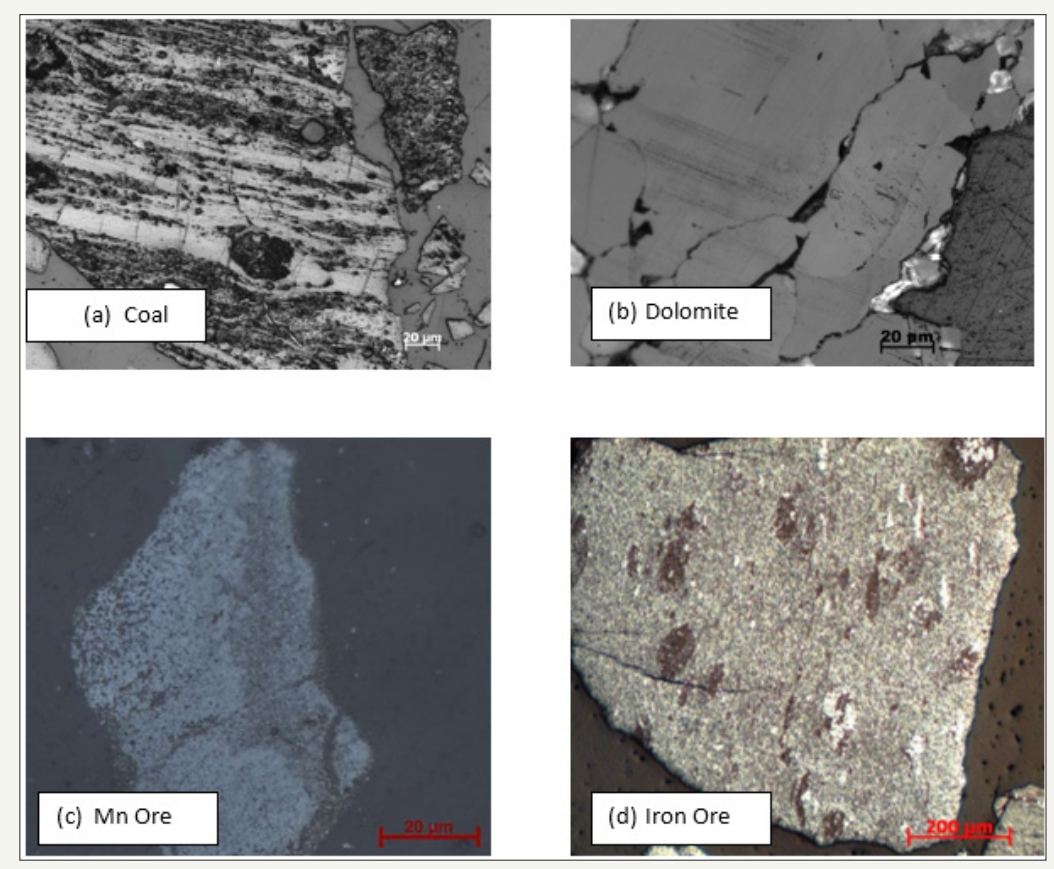

Figure 1: Microscopic views of particle surfaces of samples.

Table 1: Properties of material studied.

\begin{tabular}{|c|c|c|c|c|}
\hline Material & Bulk Density $\mathbf{( g / c c )}$ & Mohs' Hardness & Porosity & Composition \\
\hline Coal & 1.51 & 2 & 1.38 & $\mathrm{C}: 45.3 \%, \mathrm{Ash}: 35.5 \%$ \\
\hline Dolomite & 2.79 & 3 & 0.78 & $\mathrm{CaO}: 28.1 \%, \mathrm{MgO}: 20.2 \%$ \\
\hline Mn ore & 2.54 & 5 & 6.7 & $\mathrm{MnO}_{2}: 46.1 \%, \mathrm{Fe}_{2} \mathrm{O}_{3}: 32.2 \%$ \\
\hline Fe ore & 3.08 & 6 & 0.46 & $\mathrm{Fe}(\mathrm{t}): 43.2 \%, \mathrm{SiO}_{2}: 40.3 \%$ \\
\hline
\end{tabular}

Dolomite: Samples were collected from Gomardih areas of Sundergarh district, Odisha, India. The major minerals present in these rocks are dolomite, quartz, and muscovite. Table 1 shows that density and Moh's hardness of studied dolomite samples were $2.7 \mathrm{~g} / \mathrm{cc}$ and 3 , respectively. Figure 1 shows the smooth and granular structure of dolomite particle.

Manganese ore: Manganese ore samples were collected from Joda area of Odisha in India. These are ferruginous ores with high iron and low $\mathrm{Mn} / \mathrm{Fe}$ ratio. These ores are inherently friable due to deposit formation conditions. It was observed that pyrolusite and psilomelane are the predominant manganese mineral along with hematite, quartz, and kaolinite. The ore samples studied shows $3.2 \mathrm{~g} / \mathrm{cc}$ density and 5 moh's hardness. Figure 1 shows rough and fractured manganese ore particle surface.

Iron ore: Banded Hematite Jasper Iron Ore samples were collected from Odisha, India. Banded Iron Formations are chemically precipitated enigmatic rocks constituting alternate iron-rich and iron-poor (amorphous silica-rich) layers. These are very hard rocks composed of hematite and Jasper. Density and Moh's hardness of studied iron ore samples are given Table 1 \& Figure 1 shows hard and fine mineral association on iron ore particles. The density of samples was measured using conventional density bottle method. As per the ASTM D854-14 procedure, $25 \mathrm{ml}$ density bottle has been taken and weights of the bottle were measured in different conditions. The porosity of samples was measured using the fluid displacement method.

Grinding studies: Samples were prepared by most commonly used coning and quartering method. 6kg ore samples were taken and 6 packets of $1 \mathrm{~kg}$ weight were made for the experimental work. Tests were conducted in a ball mill (Length: $0.56 \mathrm{~m}$ Diameter: $0.5 \mathrm{~m}$, No. of lifter: 2) using steel balls. Experiments were conducted at three different critical mill speeds (45, 70 and 90\%) and mill 
volume was filled between $30-50 \%$ of total volume. Size analysis was performed using sieves of $1,0.5,0.25,0.15,0.106$ and $0.053 \mathrm{~mm}$.

Dry grinding: Ball milling of one kg sample was carried out using $4 \mathrm{~kg}$ steel balls of $40 \mathrm{~mm}$ diameter for two hours at $45 \%$ the critical speed of ball mill. Five hundred grams of the ground materials were taken for a screening test. The wet screening test was performed using Retsch Sieve Shaker AS200 control for each sample and the samples were dried before taking the weights.

Wet grinding: Wet milling was carried out in a similar matter as dry grinding was done at three different mill speed which 45,70

\section{Results and Discussion}

\section{Effect of grinding methods on particle size distribution}
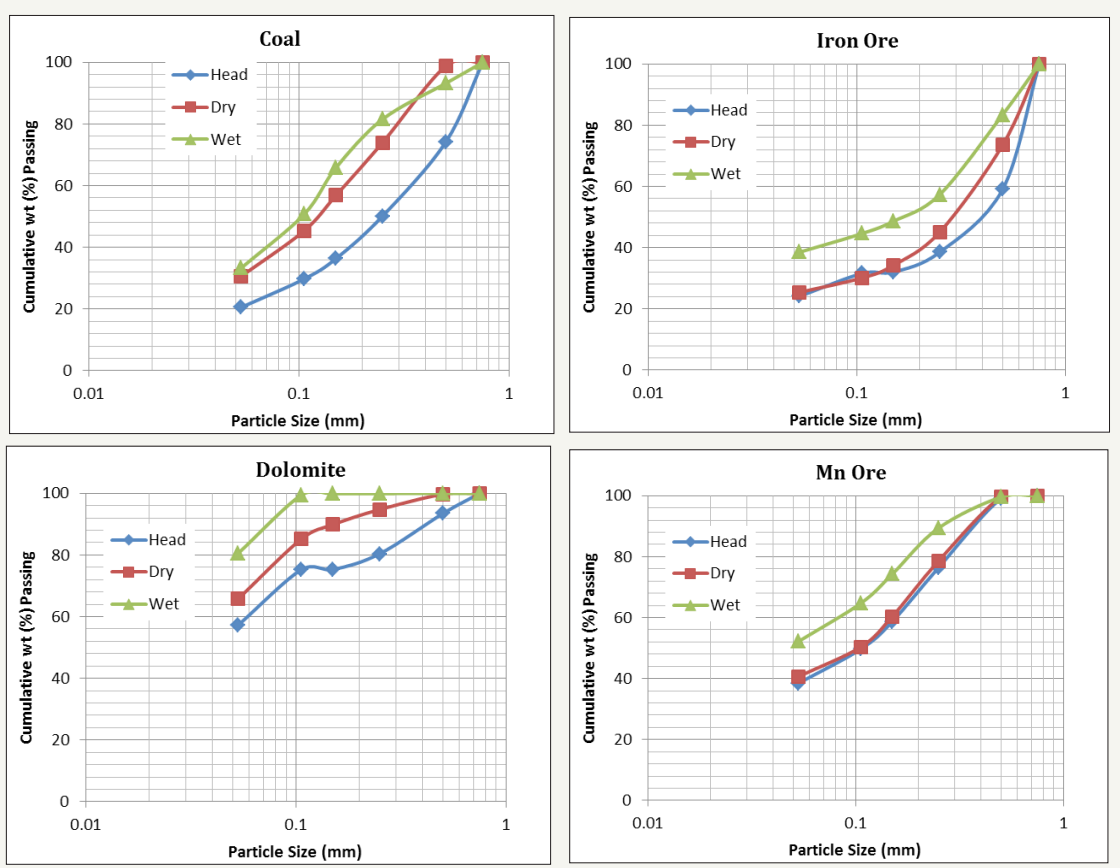

Figure 2: Comparison of dry and wet grinding of different morphology mineral matters.
Material density, angularity, and size distribution dictate the flow of material inside the mill and it also impacts the packing of particles inside the mill which effect breakage of particles during milling. Figure 2 shows a comparative analysis of size distribution of these four materials in dry and wet grinding conditions. It shows that coal and dolomite are easy to grind materials by dry grinding method whereas iron and manganese ores are suitable for wet grinding. It was seen that wet grinding improve the material fineness than dry grinding and maximum $15 \%$ improvement in $\mathrm{D}_{80}$ was seen for iron ore samples. The lowest $8 \%$ improvement in $\mathrm{D}_{80}$ was seen during dry grinding of coal particles. Dolomite shown a consistent difference in wet and dry size distribution whereas for metallic minerals difference was more prominent in case of fine sizes which indicate that presence of water increases the flowability of particles which erode inside the mill and generate more fines. In the case of coal, it could be mainly due to its bedded structure and low density which cause its particles adjustment in the slurry to minimize the impact of balls and attrition during grinding. But this effect is less on the bigger size particles due to weight and these and $90 \%$ of the critical speed of ball mill. The slurry was made using one kg ore and four liters of water. Once the sample was taken out, the wet screening test was performed.

Characterization of samples: Two-gram samples from the ground samples were taken and microscopic samples were prepared. Microscopic studies were carried out to study the L/D ratio of particles present in the samples ground in different grinding conditions. Image analyzer microscope AXIOSKOP-2 with software Axiovision 4.3 has been used for analysis of images. size particles ground more in wet grinding than dry grinding. So, it can be surmised that the presence of water and its properties play a more crucial role during grinding of heavier materials and lowdensity materials should not be ground using water.

Table 2: Weighted average diameters $(\mu \mathrm{m})$ for head, dry and wet ground samples.

\begin{tabular}{|c|c|c|c|}
\hline Material & Head & Dry $\left(\mathbf{R}_{\mathbf{4 5 \%}} \mathbf{)}\right.$ & Wet $\left(\mathbf{R}_{\mathbf{4 5 \%}} \mathbf{)}\right.$ \\
\hline Coal & 300 & 169 & 159 \\
\hline Dolomite & 130 & 69 & 42 \\
\hline Manganese & 157 & 149 & 107 \\
\hline Iron Ore & 359 & 309 & 239 \\
\hline
\end{tabular}

Table 2 \& 3 shows a comparative analysis of the impact of dry and wet grinding on different size particles. Table 2 shows that the weighted average diameter (mass of fractionx mean size of the fraction) shown reduction for all the materials while grinding methods changes from dry and wet. Analysis of data indicates that wet grinding could able to reduce the weighted average particle diameter by $3.3,20.7,26.7$ and $19.5 \%$ lower than dry grinding 
respectively for coal, dolomite, manganese and iron ores. It can be seen that for dolomite and coal the value reduces but there is not a much significant difference in wet and dry grinding as they both are light materials. For manganese, the value does not change much for dry grinding. For iron ore, the weighted average diameter decreases significantly when first ground dry and then wet.

Table 3 shows fines $(<0.053 \mathrm{~mm})$ generated during grinding. It shows that there is a linear increment in an increase in fines generation by wet grinding as the density of ores increases but coal follows a different pattern mainly due to its higher porosity. It shows that $2.7,4.5,11.5$ and $3.11 \%$ more fines are generated by wet grinding than dry grinding respectively for coal, dolomite, manganese and iron ores. It shows that fines generation during dry grinding shows a reducing trend with increased density as well as hardness but for wet grinding fined generation shown an increasing trend for increased density and hardness. It is known that abrasion contributes more in the superfine generation and impact breakage generates uniform size redistribution. In this case, abrasion could able to produce higher fines for coal and dolomite in dry grinding but could not able to produce fines for hard manganese and iron ores. In wet grinding dolomite and coal particles dispersed in the slurry and lower abrasion resulted into reduced fines generation whereas for manganese and iron ore the new particles got the opportunity for abrasion and contributed in fines generation. So, nonuniformity in fines generation in dry and wet grinding indicates that material morphology plays the vital role during fines generation.
Table 3: Cumulative mass (\%) passed through the sieve at particle size $0.053 \mathrm{~mm}$.

\begin{tabular}{|c|c|c|c|}
\hline Material & Head & $\operatorname{Dry}\left(\mathbf{R}_{\mathbf{4 5 \%}}\right)$ & $\operatorname{Wet}\left(\mathbf{R}_{\mathbf{4 5 \%}}\right)$ \\
\hline Coal & 20.51 & 30.58 & 33.25 \\
\hline Dolomite & 57.22 & 65.76 & 70.27 \\
\hline Manganese & 38.47 & 40.66 & 52.19 \\
\hline Iron Ore & 24.11 & 25.42 & 38.53 \\
\hline
\end{tabular}

\section{Effect of materials morphology on wet grinding}

The effect of increased mill speed on particles size distribution is shown in the Figure 3. It shows that coal is the most sensitive and initial increase in mill speed cause rapid reduction in particle $\mathrm{D}_{80}$ but after that, it got stabilize. This indicates that there will be an optimum mill speed to achieve the best results with optimum energy consumption during grinding. Dolomite is least sensitive towards increased mill speed and does not show significant variation in particle size reduction with increased mill speed. Iron and manganese show a consistent reduction in $\mathrm{D}_{80}$ due to increased mill speed. Both the materials show 30 to 40 -micron reduction in $\mathrm{D}_{80}$ for each 15unit increase mill speed. Figure 3 also shows that rapid size reduction is related to softness as well as brittleness. So, coal has a maximum slope whereas manganese has the lowest slope.

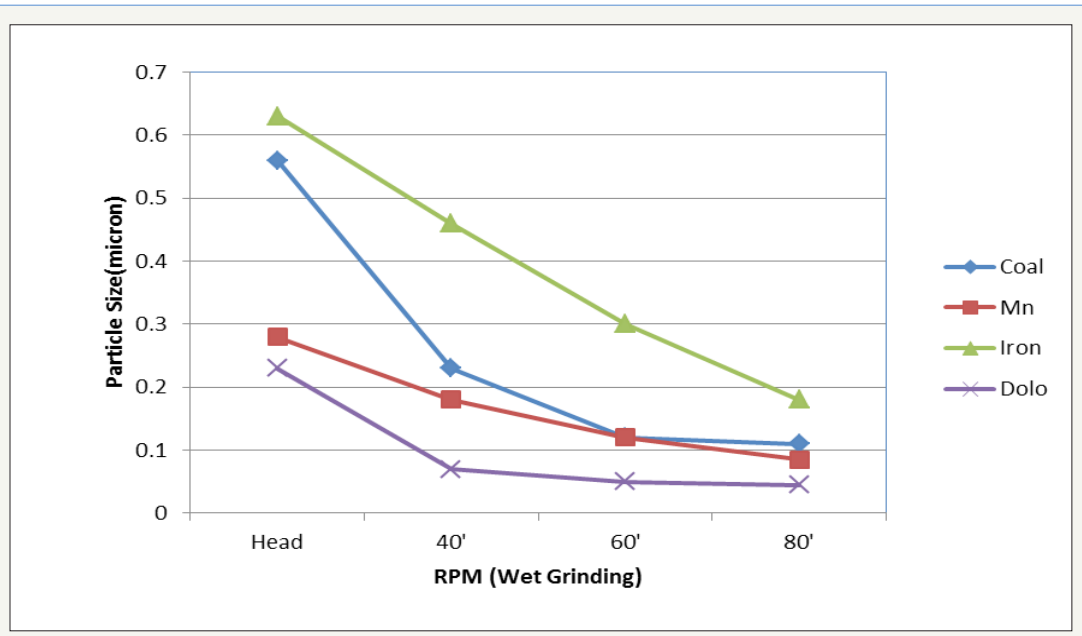

Figure 3: Effect of mill speed on the wet grinding of different morphology mineral matters.

Table 4: Effect of mill speed on $<0.053 \mathrm{~mm}(\%)$ size particle during wet grinding of mineral matters.

\begin{tabular}{|c|c|c|c|c|}
\hline Mill Speed & Coal & Dolomite & Mn Ore & Iron Ore \\
\hline $\mathrm{R}_{45 \%}$ & 33.25 & 70.27 & 52.19 & 38.53 \\
\hline $\mathrm{R}_{70 \%}$ & 55.83 & 80.51 & 55.33 & 47.52 \\
\hline $\mathrm{R}_{90 \%}$ & 59.13 & 87.23 & 67.81 & 48.89 \\
\hline
\end{tabular}

Table 4 shows the weighted average diameter of the particles ground at different mill speeds using different mineral matters. As speed increases the fractions of finer particles increase and weighted average diameter decrease. For dolomite, there is not much difference in weighted average diameter because it already has finer particles and it does not affect by increased speed. Iron is the hardest and heaviest material among all studied samples and weighted average diameters for this material. Table 4 shows the fraction of cumulative below $0.053 \mathrm{~mm}$ micron size with increase in speed. For iron ore and coal, the significant difference is not seen between wet grinding at a $20 \%$ increase in ground speed. It was seen that during the wet grinding, fines generation reduces with mill speed for different density materials. It was seen that below $0.053 \mathrm{~mm}$ fraction increased by 25.9, 16.9, 15.6 and $10.3 \%$ for coal, dolomite, and manganese and iron ores, respectively. The low-density materials are more sensitive to mill speed and reasons are their dispersion among the grinding balls. High-density ore 
particles move in the bottom and mostly broken by impact and abrasion, but light density material got agitated and broken by inter ball collision also. The comparative analysis given in Fig.4 shows that fine generation during dry grinding depends more on density and hardness whereas in case of wet grinding hardness and porosity become the more prominent factors. It is also a fact the all these properties are interdependent, and their internal dependence may also impact the results.

\section{Comparison of grinding methodology on power con- sumption}

Power consumption during grinding depends on the weight of the material inside the ball mill and bond work index of the material. In wet grinding, additional four-litre water has been added which contributed additional weight will increase the power consumption and economic viability will be impacted by overall improvement in $\mathrm{D}_{80}$. Table 5 shows the theoretical $\mathrm{D}_{80}$ which expected to be compensated by increased power consumption. Table 5 shows that in case of light minerals the wet grinding is not effective and $\mathrm{D}_{80}$ achieved by wet grinding could not able to compensate the increased energy inputs but for heavy minerals, it showed acceptable results.

Table 5: Impact of grinding conditions on energy consumption ( $\mathrm{kWh} /$ ton).

\begin{tabular}{|c|c|c|c|c|c|}
\hline \multirow{2}{*}{ Material } & \multicolumn{5}{|c|}{ Particle size (D $\mathbf{8 0}$ By Graph) } \\
\cline { 2 - 6 } & Head & Dry & Wet & Theoretical & \%, Impact \\
\hline Coal & 560 & 300 & 250 & 203 & -8 \\
\hline Dolomite & 230 & 85 & 70 & 49 & -3 \\
\hline Manganese & 280 & 250 & 180 & 229 & 21 \\
\hline Iron Ore & 630 & 560 & 460 & 512 & 8 \\
\hline
\end{tabular}

\section{Effect on particle shape}

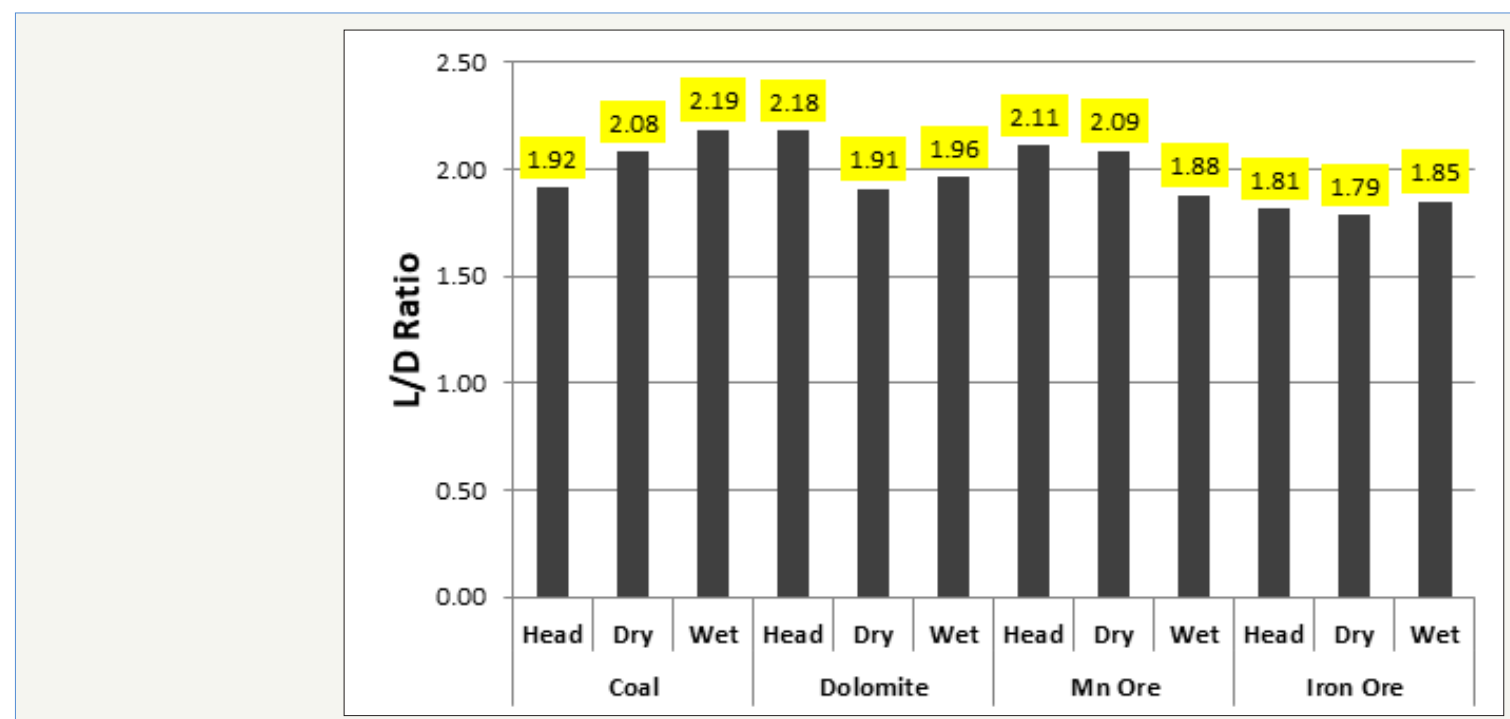

Figure 4: Effect of different physical properties on fines generation during dry and wet grinding.

Figure 4 shows the variation of $\mathrm{L} / \mathrm{D}$ ratio of different particles during dry and wet grinding conditions. It is clearly visible that materials do not follow a certain pattern because of varying structure, grain sizes, and hardness. It is seen that light particles (dolomite and coal) have higher L/D ratio in the case of wet grinding than dry grinding but for heavier particles, there is not any general observation. Coal is the only material which show an increased trend in L/D ratio which means that the particles formed more angular in shape than the head sample. Since L/D ratio is highest for manganese ore initially, and it is also a high-density material thus by adding water (wet grinding), the particles broke into more circular shapes than in head sample while dry grinding does not change its shape much. Dolomite also has more of angular shaped particles in the head sample and it is also a low density and finegrained material thus the particles form more circular shapes when ground. In the case of iron ore, the shape does not very much it is more or less the same in all the three cases. It is also observed that dry grinding does not affect the shape of hard and density particles much. Wet grinding usually produces more angular particles than dry grinding and less sensitive towards material characteristics. It was seen that L/D has increased for three ores and reduced only for one case during dry to wet grinding. It indicates that chipping is more prominent in the case for wet grinding whereas abrasion is more prominent in case of dry grinding.

\section{Conclusion}

Material morphology plays an important role during the grinding of ores. Dry grinding should be a preferred method for grinding of light and soft materials whereas wet grinding should be applied for heavy and hard materials. It was found that light and soft materials (Coal and Dolomite) show relatively less variation in grinding characteristics than the heavier and hard minerals matter (Mn \& Fe Ores). Particle angularity is more impacted by wet grinding than dry grinding. Dolomite shows the lowest $8 \%$ difference in $\mathrm{D}_{80}$ of particles whereas manganese ore shows the highest $29 \%$ variation in $\mathrm{D}_{80}$ of particles for dry and wet grinding in same conditions. Low-density materials are less sensitive towards grinding parameters during wet grinding than the high- 
density materials. The increased power consumption due to the addition of water in the mill could not be compensated by enough reduction in particle size for low-density materials but for highdensity materials, it is energy saving. It was found the wet grinding can increase the fineness $\left(\mathrm{D}_{80}\right)$ for coal, dolomite, manganese ores and iron ores by $8.9,6.5,25$, and $15.8 \%$, respectively. Variation in $\mathrm{D} / \mathrm{L}$ indicates that abrasion contributes more prominently in dry grinding and chipping is more prominent in wet grinding. These effects can be helpful for selection of proper slurry rheology and grinding method for materials of different density and hardness.

\section{References}

1. Rumpf H (1973) Physical aspects of comminution and a new formulation of a law of comminution. Powder Technolology 7(3): 145-159.

2. Vogel L, Peukert W (2004) Determination of material properties relevant to grinding by practicable lab scale milling tests. Int J Miner Process 74: S329-S338.

3. Ruiz M D (1966) Some technological characteristics of twenty-six Brazilian rock types. Proc $1^{\text {st }}$ Congo Int Soc Rock 1: 115-119.

4. Rafael L, Salganik LR, Gotlib VA (1997) Effect of structure on environmentally assisted subcritical crack growth in brittle materials. Int J Fract 87(1): 21.

5. Rehbinder A (1931) Reduction of hardness by adsorption scelerometry and the physics of dispersed systems. Physik 72: 191-205.

6. Hockings WA, Volin ME, Mular AL (1965) Effect of suspending fluid viscosity on batch mill grinding. Trans AIME 131: 59-62.

7. Hanna KM, Gamal AE (1977) The effect of dispersing agents on the fine grinding of limestone. Powder Technol 17(1): 19-25.

8. El Shall H, Somasundaran P (1984) Physico-chemical aspects of grinding: a review of the use of additives. Powder Technol 38(3): 275-293.
9. Yang SC (2006) Density effect on mixing and segregation processes in a vibrated binary granular mixture. Powder Technol 164(2): 65-74.

10. Brown GJ, Reddish DJ (1997) Experimental relations between rock fracture toughness and density. Int J Rock Mech Min Sci 34(1): 153-155.

11. Alber M, Brardt A (2003) Factors influencing fracture toughness KIC from simple screening tests. Int J Rock Mech Min Sci 40(5): 779-784.

12. Brun R, Lucien ZD (1995) Shock waves @ marseille IV: shock structure and kinematics, blast waves and detonations, Springer Berlin Heidelberg, USA.

13. Yekeler M, Ozkan A (2002) Determination of the breakage and wetting parameters of calcite and their correlations. Part Part Syst Charact 19(6): 419-425

14. Liu D, Vasudevan TV, Somasudaran P, Harrris CC (1993) Effect of wet versus dry grinding on rejection of pyrite and non-pyritic minerals from pittsburgh No 8 coal by flotation. Coal Prepar 13: 63-72.

15. Özkan A, Yekeler M (2002) Kinetics of wet versus dry grinding of lignite by a porcelain mill. Indian J Eng Material S 9: 181-186.

16. Kotake N, Kuboki M, Kiya S, Kanda Y (2011) Influence of dry and wet grinding conditions on fineness and shape of particle size distribution of product in a ball mill. Advanced Powder Technology 22(1): 86-92.

17. He M, Wang Y, Forssberg E (2006) Parameter effects on wet ultrafine grinding of limestone through slurry rheology in a stirred media mill. Powder Technol 161(1): 10-21.

18. ASTM D854-14 (2014) Standard test methods for specific gravity of soil solids by water pycnometer, ASTM International, West Conshohocken, Pennsylvania, USA.

19. Wills BA, Napier M (2006) In: Mineral processing technology: An introduction to the practical aspects of ore treatment and mineral recovery, $\left(7^{\text {th }}\right.$ edn), Elsevier Science \& Technology Books. Burlington, Massachusetts, USA, pp. 400-408.
Creative Commons Attribution 4.0 International License

For possible submissions Click Here

\section{Submit Article}

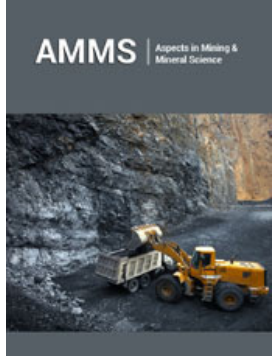

Aspects in Mining \& Mineral Science

\section{Benefits of Publishing with us}

- High-level peer review and editorial services

- Freely accessible online immediately upon publication

- Authors retain the copyright to their work

- Licensing it under a Creative Commons license

- Visibility through different online platforms 